\title{
(6) OPEN ACCESS \\ Prevalence of diabetic retinopathy in individuals with type 2 diabetes who had recorded diabetic retinopathy from retinal photographs in Catalonia (Spain)
}

\author{
Antonio Rodriguez-Poncelas, ${ }^{1,2}$ Sònia Miravet-Jiménez, ${ }^{3,4}$ Aina Casellas, ${ }^{5}$ \\ Joan Francesc Barrot-De La Puente, ${ }^{2,6}$ Josep Franch-Nadal, 4,7 Flora López-Simarro, 3,4 \\ Manel Mata-Cases, ${ }^{4,8}$ Xavier Mundet-Tuduríi,9
}

For numbered affiliations see end of article.

\section{Correspondence to} Professor Xavier MundetTudurí, Unitat de Suport a la Recerca Barcelona Ciutat, Institut Universitari d'Investigació en Atenció Primària Jordi Gol (IDIAP Jordi Gol), Sardenya 375, Barcelona 08025, Spain; xavier.mundet@uab.cat

Received 3 February 2015 Revised 9 April 2015 Accepted 26 May 2015 Published Online First 18 June 2015

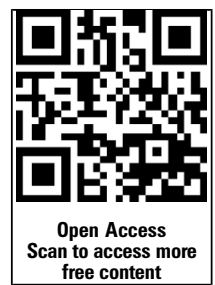

CrossMark

To cite: RodriguezPoncelas A, MiravetJiménez $\mathrm{S}$, Casellas $\mathrm{A}$, et al. $\mathrm{Br} J$ Ophthalmol 2015:99:1628-1633.

\section{ABSTRACT \\ Background/aims Retinal photography with a non- mydriatic camera is the method currently employed for diabetic retinography (DR) screening. We designed this study in order to evaluate the prevalence and severity of $D R$, and associated risk factors, in patients with type 2 diabetes (T2DM) screened in Catalan Primary Health Care.}

Methods Retrospective, cross-sectional, population based study performed in Catalonia (Spain) with patients with T2DM, aged between 30 years and 90 years (on 31 December 2012) screened with retinal photography and whose DR category was recorded in their medical records. DR was classified as: no apparent retinopathy (no DR), mild non-proliferative DR (mild NPDR), moderate NPDR, severe NPDR, proliferative DR (PDR) and diabetic macular oedema (DMO). Non-vision threatening DR (non-VTDR) included mild and moderate NPDR; VTDR included severe NPDR, PDR and DMO. Clinical data were obtained retrospectively from the SIDIAP database (System for Research and Development in Primary (are).

Results 108723 patients with T2DM had been screened with retinal photography. The prevalence of any kind of DR was $12.3 \%$ (95\% Cl $12.1 \%$ to $12.5 \%)$. NonVTDR and VTDR were present in 10.8\% (mild 7.5\% and moderate NPDR $3.3 \%$ ) and $1.4 \%$ (severe NPDR $0.86 \%$, PDR $0.36 \%$ and DMO $0.18 \%$ ) of the study patients, respectively.

Conclusions The prevalence of any type of DR in patients with T2DM screened with retinal photography was lower when compared with earlier studies.

\section{INTRODUCTION}

Diabetic retinopathy (DR) is a major microvascular complication in diabetics. It particularly affects patients with type 2 diabetes (T2DM) whose vision may be threatened by diabetic macular oedema (DMO) and proliferative DR (PDR). In developed countries these two conditions are the principal cause of blindness in adults of working age and are responsible for a worsening in quality of life. ${ }^{1}$ The presence and severity of DR is related to cardiovascular risk factors and, consequently, a greater incidence of cardiovascular disease. ${ }^{2}$

Previous studies have shown a considerable variation in DR prevalence. Factors such as population characteristics, screening techniques employed (direct ophthalmological examination or digital photography) and type of study performed, all hinder comparisons among studies. Depending on the country, the prevalence rate of direct ophthalmological screening ranges from $40.3 \%$ in the study by Kempen et $a l ;{ }^{3} 34.6 \%$ in the meta-analysis by Yau et $a l ;{ }^{4} 33.2 \%$ in the study by Wong et al $;{ }^{5}$ to $27.9 \%$ in the work from Ruta et al. ${ }^{6}$ DR prevalence in Spain also differs according to the authors. The results vary from $20.9 \%$ to $26.1 \% .^{78}$

In studies that employ retinal photography in DR screening, prevalence also differs: $19 \%$ in the $\mathrm{UK}^{9}$ (patients with recently diagnosed T2DM), 29\% in the USA, ${ }^{10} 34.6 \%$ in Sweden, ${ }^{11}$ and in the study carried out by Ruta $e t a l^{6}$ in developing and developed countries between $10.1 \%$ and $48.1 \%$. The variations observed among the countries could be explained by the screening techniques employed (direct ophthalmological examination or digital photography) and the type of study performed. Factors such as these plus distinct methodologies and population characteristics all hinder comparisons among studies.

In spite of an overall increase in T2DM prevalence in Spain ${ }^{12}$ and abroad, ${ }^{13}$ a decrease in DR prevalence, particularly vision threatening DR (VTDR), has been observed. ${ }^{14}$ This reduction could be a result of increased care for patients with diabetes and an earlier detection of T2DM and $\mathrm{DR},{ }^{15}$ the time of progression of diabetes ${ }^{1}$; poor control of glycaemia, ${ }^{16}$ blood pressure, ${ }^{16}$ dyslipidaemia $;{ }^{17}$ and higher levels of the urinary albumin to creatine ratio (UACR) ${ }^{18}$ have been identified as risk factors for the onset and progression of DR. Hyperglycaemia plays a key role in this process; ${ }^{19}$ and a strict glycaemic control is recommended, particularly during the initial phases of the disease. In addition, the control of blood pressure ${ }^{20}$ and regular examinations of the ocular fundus are advised to diminish DR severity and incidence.

It is important to be aware of DR prevalence as it is a reliable indicator of microvascular complications and the impact that a good control of the disease can have on health results. However, the DR prevalence figures published in the literature do not correspond to those we have observed in primary healthcare clinical practice; an issue that can have repercussions on the correct planning and orientation of resources. This study was performed in order to observe the prevalence of DR, and its associated risk factors, in 
patients with T2DM screened with retinal photography, and whose DR category was recorded in their medical records, at the Catalonian primary healthcare services (Spain).

\section{MATERIALS AND METHODS}

\section{Study, design, settings and population}

A population-based, descriptive study was performed in Catalonia (Spain) with patients with T2DM. Catalonia is a region in the north-east of Spain and has a public health system that covers $100 \%$ of the population. Most inhabitants $(70 \%)$ concentrate in urban areas. All patients aged 30-90 years with a diagnosis of T2DM (International Classification of Diseases 10 codes E11 and E14) before 31 December 2012 were included. Of a total of 3755038 individuals aged 30-90 years, 329419 patients with T2DM (8.8\%) were identified and 108723 (33\%) had been screened with retinal photography and all study variables recorded in the electronic medical record between 1 January 2008 and 31 December 2012.

Information for this study came from the SIDIAP (System for Research and Development in Primary Care) an electronic database containing all the patients' medical records. The SIDIAP includes data from the primary healthcare electronic medical records named e-CAP (ECAP) on demographic information, appointment dates with doctors and nurses, clinical diagnoses, clinical variables, prescriptions written, referrals to specialists and hospitals, results from laboratory tests, and medication sold by pharmacies. The quality of SIDIAP data has been previously documented, and the database has been widely used to study the epidemiology of a number of health outcomes. ${ }^{21}$

\section{Assessment of DR}

The use of retinal photography for the detection of DR has been validated. ${ }^{22}$ Digital colour images are captured from each eye and the severity of DR is categorised according to the international clinical DR severity scales recommended by the Global Diabetic Retinopathy Project Group ${ }^{23}$ as: no apparent retinopathy (no DR), mild non-proliferative DR (mild NPDR), moderate NPDR, severe NPDR, proliferative DR (PDR) and DMO. All patients should have had at least one fundus photo recorded. In the case of patients having more than one retinal photograph between 1 January 2008 and 31 December 2012, the last one was used for analysis. Each patient was given a DR according to the worst eye. We took two digital colour images from each eye: one $45^{\circ}$ centred midway between the macula and the optic disc and the other centred on the macula. In our study, retinal photography was performed by trained personnel using a nonmydriatic camera. Subsequently, in the primary healthcare centre, a family physician trained in reading eye fundus images registered the result in the patient's medical records.

\section{Measures of kidney function}

Serum creatine levels and UACR were determined and the following definitions established: normoalbuminuria (UACR $<30 \mathrm{mg} / \mathrm{g}$ ), microalbuminuria (UACR 30-299 mg/g), and macroalbuminuria (UACR $\geq 300 \mathrm{mg} / \mathrm{g}$ ). The estimated glomerular filtration ratio (eGFR) was calculated according to the Modification of Diet in Renal Disease equation.

\section{Clinical variables}

The following data were obtained from each patient: age, gender, age at diagnosis of diabetes, duration of diabetes and glycated haemoglobin levels (A1C). Cardiovascular risk factors including body mass index, blood lipids, total cholesterol, low density lipoprotein cholesterol, high density lipoprotein (HDL) cholesterol,
non-HDL cholesterol, blood pressure (systolic and diastolic), pulse pressure and smoking status according to the last condition registered before 31 December 2012, were collected. Data for clinical variables were gathered from the 15 months prior to the cut-off date with the exception of blood pressure, pulse pressure and body mass index, which were obtained from the previous 12 months. Additional data was gathered on medication.

\section{Statistical analysis}

DR prevalence was calculated assuming a binominal distribution on which the CI was based. Patient characteristics were compared according to DR presence and severity by analysis of variance (ANOVA) for the continuous variables and Pearson's $\chi^{2}$ test for the categorical ones. The level of statistical significance was set at $\mathrm{p}<0.05$. All calculations were performed with StataCorp V.13.0 (Stata Statistical Software, College Station, Texas, USA: StataCorp LP).

\section{RESULTS}

In our study 108723 T2DM had been screened with retinal photography and their DR category recorded in their medical records.

The overall prevalence of any DR was $12.2 \%$ (CI $12.1 \%$ to 12.5\%): $7.5 \%$ mild NPDR, 3.3\% moderate NPDR, $0.86 \%$ severe NPDR, $0.36 \%$ PDR. DMO was present in $0.18 \%$ of the patients alone or associated with other DR lesions. Prevalence (figure 1) of VTDR and non-VTDR was $1.4 \%$ and $10.8 \%$ (CI $1.4 \%$ to $1.5 \%$ ), respectively. Table 1 shows the characteristics of the participants with and without retinal photography screening. The group without retinal photography was older (69.4 years vs 66.9 years), had a shorter T2DM progression time (7.5 years vs 7.8 years), was diagnosed with T2DM at an older age (61.9 years vs 59.2 years), had a higher percentage of eGFR $<60 \mathrm{~mL} /$ $\mathrm{min} / 1.73 \mathrm{~m}^{2}$ (22.9 vs 19.7), and higher levels of UACR (45.4 $\mathrm{mg} / \mathrm{g}$ vs $36.1 \mathrm{mg} / \mathrm{g})$.

Table 2 presents the clinical and metabolic characteristics of the 108723 participants with retinal photography and recorded DR category. Of these $56.2 \%$ were men. The mean age was $66.9(11.0 \%)$ years, mean duration of diabetes was $7.8(5.1 \%)$ years, and mean A1C level was $7.2(1.3 \%)$. In comparison to patients without DR, those with some kind of DR were older and with a greater percentage of hypertension. They also had a longer duration of diabetes, higher A1C levels, higher systolic blood pressure, lower diastolic blood pressure and higher pulse pressure. Patients with DR used more insulin than those without. Participants with some kind of DR had a higher percentage of eGFR levels $<60 \mathrm{~mL} / \mathrm{min} / 1.73 \mathrm{~m}^{2}$ and greater values of UACR than those without.

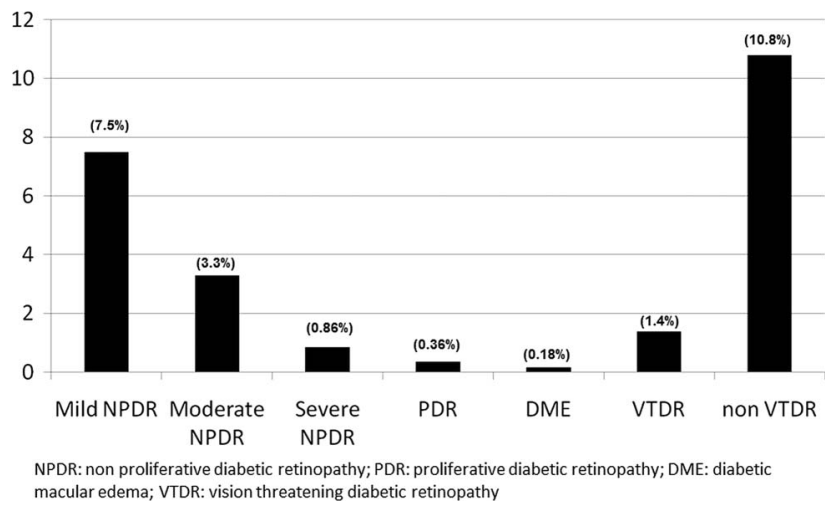

Figure 1 Prevalence of diabetic retinopathy. 
Table 1 Characteristics of patients with and without digital photography

\begin{tabular}{|c|c|c|c|c|}
\hline $\mathrm{N}(\%)$ & $\begin{array}{l}\text { Global } \\
329419 \text { (100) }\end{array}$ & $\begin{array}{l}\text { Without DP } \\
220696 \text { (67) }\end{array}$ & $\begin{array}{l}\text { With DP } \\
108723(33)\end{array}$ & ${ }^{*} \mathrm{P}$ value \\
\hline Sex, n (\%) & & & & $<0.001$ \\
\hline Male & $180198(54.7)$ & $119087(54.0)$ & $61111(56.2)$ & \\
\hline Female & $149221(45.3)$ & $101609(46.0)$ & $47612(43.8)$ & \\
\hline Age (years) $(n=329419)$ & $68.6(11.7)$ & $69.4(11.9)$ & $66.9(11.0)$ & $<0.001$ \\
\hline BMI $\left(\mathrm{kg} / \mathrm{m}^{2}, \mathrm{SD}\right)(\mathrm{n}=329419)$ & $30.1(5.1)$ & $30.1(5.2)$ & $30.2(5.0)$ & $<0.001$ \\
\hline Diabetes time of progress (years) ( $n=329419$ ) & $7.6(5.6)$ & $7.5(5.8)$ & $7.8(5.1)$ & $<0.001$ \\
\hline Age of diabetes diagnosis $(n=329419)$ & $61.0(11.4)$ & $61.9(11.7)$ & $59.2(10.7)$ & $<0.001$ \\
\hline A1C (\%) $(n=263690)$ & $7.2(1.3)$ & $7.2(1.3)$ & $7.2(1.3)$ & 0.631 \\
\hline Hypertension, $n(\%)$ ( $n=264743)$ & 80.4 & 80.5 & 80.1 & 0.003 \\
\hline SBP $(m m ~ H g) ~(n=279030)$ & $134.8(13.2)$ & $135.0(13.5)$ & $134.5(12.5)$ & $<0.001$ \\
\hline $\mathrm{DBP}(\mathrm{mm} \mathrm{Hg})(\mathrm{n}=279030)$ & $75.2(8.6)$ & $75.0(8.8)$ & $75.6(8.3)$ & $<0.001$ \\
\hline$P P(m m ~ H g)(n=279030)$ & $59.6(12.4)$ & $60.0(12.7)$ & $58.9(11.9)$ & $<0.001$ \\
\hline Non-HDL cholesterol (mg/dL) $(\mathrm{n}=248610)$ & $137.0(36.9)$ & $137.0(37.4)$ & $136.9(36.0)$ & 0.461 \\
\hline Triglycerides $(\mathrm{mg} / \mathrm{dL})(\mathrm{n}=258046)$ & $154.5(102.6)$ & $153.5(103.3)$ & $156.4(101.2)$ & $<0.001$ \\
\hline Creatine $(\mathrm{mg} / \mathrm{dL})(\mathrm{n}=265898)$ & $0.9(0.4)$ & $0.9(0.4)$ & $0.9(0.3)$ & $<0.001$ \\
\hline eGFR $\left(\mathrm{mL} / \mathrm{min} / 1.73 \mathrm{~m}^{2}\right)<60, \mathrm{n}(\%)(\mathrm{n}=265898)$ & $57957(21.8)$ & $39431(22.9)$ & $18526(19.7)$ & $<0.001$ \\
\hline UACR $(\mathrm{mg} / \mathrm{g})(\mathrm{n}=149526)$ & $41.8(155.1)$ & $45.4(163.4)$ & $36.1(141.3)$ & $<0.001$ \\
\hline
\end{tabular}

${ }^{*} p$ Value for comparison of groups with Pearson's $\chi^{2}$ test for qualitative variables and ANOVA for the quantitative ones. Values are expressed as $n$ (\%) and mean (SD).

A1C, glycated haemoglobin; BMI, body mass index; DBP, diastolic blood pressure; DP, digital photography; eGFR, estimated glomerular filtration ratio; PP, pulse pressure; SBP, systolic blood pressure; UACR, urinary albumin-to-creatine ratio.

Table 3 shows the risk factors associated with DR. The prevalence of any kind of DR increased with the duration of diabetes $(6.9 \%<5$ years and $23.7 \% \quad>15$ years $)$; higher A1C levels $(8.4 \% \leq 7 \%$ and $22.9>9 \%)$; poorer blood pressure $(10.9 \%<140 / 90$ and $15.4 \% \geq 140 / 90)$; and hypertension (9.1-13.1\%). There was a trend towards a lower prevalence of any DR in patients with non HDL-cholesterol $\geq 3.3 \mathrm{mmol} / \mathrm{L}$.

Table 2 Clinical and laboratory characteristics of patients without DR, with NPDR, PDR and DMO

\begin{tabular}{|c|c|c|c|c|c|c|}
\hline & Global & No DR & NPDR & PDR & DMO & P value* \\
\hline $\mathrm{N}$ & 108723 & 95336 & 12788 & 400 & 199 & \\
\hline Sex (M), n (\%) & $61111(56.2)$ & $53642(56.3)$ & $7137(55.8)$ & $216(54.0)$ & $116(58.3)$ & 0.553 \\
\hline Age (years) ( $n=108723$ ) & $66.9(11.0)$ & $66.7(11.0)$ & $68.5(10.9)$ & $71.3(9.7)$ & $69.8(10.9)$ & $<0.001$ \\
\hline BMI $\left(\mathrm{Kg} / \mathrm{m}^{2}\right)(\mathrm{n}=89610)$ & $30.2(5.0)$ & $30.2(5.0)$ & $30.0(5.1)$ & $30.1(4.6)$ & $29.5(4.4)$ & 0.002 \\
\hline $\begin{array}{l}\text { Diabetes time of progress (years) } \\
(n=108723)\end{array}$ & $7.8(5.1)$ & $7.5(4.9)$ & $9.8(5.9)$ & $10.7(5.8)$ & $9.6(5.8)$ & $<0.001$ \\
\hline $\begin{array}{l}\text { Age of diabetes diagnosis (years) } \\
(n=108723)\end{array}$ & $59.2(10.7)$ & $59.2(10.6)$ & $58.6(11.2)$ & $60.6(10.8)$ & $60.2(11.4)$ & $<0.001$ \\
\hline A1C (\%) (n=95 126) & $7.2(1.3)$ & $7.2(1.3)$ & $7.7(1.5)$ & $8.0(1.6)$ & $7.7(1.5)$ & $<0.001$ \\
\hline Insulin treatment, $\mathrm{n}(\%)$ & $18452(17.0)$ & $13338(14.0)$ & 4819 (37.7) & $218(54.5)$ & 77 (38.7) & $<0.001$ \\
\hline Hypertension, n (\%) & $87056(80.1)$ & $75645(79.3)$ & $10869(85.0)$ & $364(91.0)$ & $178(89.4)$ & $<0.001$ \\
\hline SBP $(m m ~ H g)(n=97646)$ & $134.5(12.5)$ & $134.1(12.3)$ & $136.9(13.4)$ & $137.9(14.2)$ & $138.9(14.5)$ & $<0.001$ \\
\hline $\mathrm{DBP}(\mathrm{mm} \mathrm{Hg})(\mathrm{n}=97646)$ & $75.6(8.3)$ & $75.7(8.3)$ & $74.7(8.6)$ & $73.4(8.7)$ & $74.3(8.9)$ & $<0.001$ \\
\hline $\mathrm{PP}(\mathrm{mm} \mathrm{Hg})(\mathrm{n}=97646)$ & $58.9(11.9)$ & $58.4(11.7)$ & $62.2(12.8)$ & $64.5(12.8)$ & $64.6(13.0)$ & $<0.001$ \\
\hline $\begin{array}{l}\text { Non-HDL cholesterol (mg/dL) } \\
(\mathrm{n}=89090)\end{array}$ & $136.9(36.0)$ & $137.5(35.8)$ & $132.4(36.9)$ & $130.1(35.3)$ & $134.9(37.7)$ & $<0.001$ \\
\hline Creatine (mg/dL) (n=93 774) & $0.9(0.3)$ & $0.9(0.3)$ & $1.0(0.4)$ & $1.1(0.5)$ & $1.0(0.9)$ & $<0.001$ \\
\hline eGFR $\left(\mathrm{mL} / \mathrm{min} / 1.73 \mathrm{~m}^{2}\right), \mathrm{n}(\%)$ & & & & & & $<0.001$ \\
\hline$\geq 60$ & $75394(80.3)$ & $66988(81.1)$ & $8082(74.3)$ & $208(63.4)$ & $116(69.9)$ & \\
\hline$<60$ & $18526(19.7)$ & 15564 (18.9) & $2792(25.7)$ & $120(36.6)$ & $50(30.1)$ & \\
\hline UACR (mg/g), n (\%) & & & & & & $<0.001$ \\
\hline$<30$ & $48860(83.0)$ & 43655 (84.5) & $5029(73.0)$ & $118(62.1)$ & $58(59.2)$ & \\
\hline $30-299$ & $8692(14.8)$ & 7081 (13.7) & $1519(22.1)$ & $58(30.5)$ & $34(34.7)$ & \\
\hline$\geq 300$ & $1294(2.2)$ & $936(1.8)$ & 338 (4.9) & $14(7.4)$ & $6(6.1)$ & \\
\hline
\end{tabular}

${ }^{*} \mathrm{p}$ Value for comparison of groups with Pearson's $\chi^{2}$ test for qualitative variables and ANOVA for the quantitative ones. Values are expressed as $n(\%)$ and mean (SD).

A1C, glycated haemoglobin; BMI, body mass index; DBP, diastolic blood pressure; DMO, macular oedema; DR, diabetic retinopathy; eGFR, estimated glomerular filtration ratio; NPDR, non-proliferative diabetic retinopathy; PDR, proliferative diabetic retinopathy; PP, pulse pressure; SBP, systolic blood pressure; UACR, urinary albumin-to-creatine ratio. 
Table 3 Patients with any kind of diabetic retinopathy and associated risk factors

\begin{tabular}{|c|c|c|c|c|c|c|c|}
\hline & $\begin{array}{l}\text { Any DR } \\
\mathrm{N}(\%)\end{array}$ & $\begin{array}{l}\text { Mild-NPDR } \\
\text { N (\%) }\end{array}$ & $\begin{array}{l}\text { Moderate-NPDR } \\
\mathrm{N}(\%)\end{array}$ & $\begin{array}{l}\text { Severe-NPDR } \\
\text { N (\%) }\end{array}$ & $\begin{array}{l}\text { PDR } \\
\mathrm{N}(\%)\end{array}$ & $\begin{array}{l}\text { DMO } \\
\mathrm{N}(\%)\end{array}$ & ${ }^{*} \mathrm{P}$ value \\
\hline Sex & & & & & & & 0.001 \\
\hline Male & 7469 (12.2) & $4464(7.29)$ & $2092(3.42)$ & $581(0.95)$ & $216(0.35)$ & $116(0.19)$ & \\
\hline Female & $5918(12.4)$ & $3680(7.71)$ & $1608(3.36)$ & $363(0.76)$ & $184(0.38)$ & $83(0.17)$ & \\
\hline Total & $13387(12.3)$ & $8144(7.48)$ & 3700 (3.39) & $944(0.86)$ & $400(0.36)$ & $199(0.18)$ & \\
\hline Diabetes time duration (years) & & & & & & & $<0.001$ \\
\hline$<5$ & $2420(6.9)$ & $1580(4.50)$ & $607(1.73)$ & $146(0.42)$ & $47(0.14)$ & $40(0.11)$ & \\
\hline $5-9$ & $5907(12.5)$ & $3633(7.68)$ & $1623(3.44)$ & $396(0.84)$ & $170(0.36)$ & $85(0.18)$ & \\
\hline $10-15$ & $3083(17.2)$ & $1847(10.31)$ & $851(4.74)$ & $221(1.23)$ & $121(0.68)$ & $43(0.24)$ & \\
\hline$>15$ & $1977(23.7)$ & $1084(12.99)$ & $619(7.43)$ & $181(2.17)$ & $62(0.74)$ & $31(0.37)$ & \\
\hline $\mathrm{A} 1 \mathrm{C}(\%)$ & & & & & & & $<0.001$ \\
\hline$\leq 7.0$ & $4360(8.4)$ & $2912(5.61)$ & $1042(2.01)$ & $236(0.45)$ & $99(0.19)$ & $71(0.14)$ & \\
\hline$>7.0$ to $<7.9$ & 3193 (13.3) & $1933(8.05)$ & $918(3.82)$ & $215(0.90)$ & $92(0.38)$ & $35(0.15)$ & \\
\hline 8 to 9 & $1868(18.4)$ & $1064(10.47)$ & $560(5.52)$ & $150(1.48)$ & $67(0.66)$ & $27(0.27)$ & \\
\hline$>9$ & $2026(22.9)$ & $1084(12.25)$ & $650(7.35)$ & $191(2.16)$ & $71(0.80)$ & $30(0.34)$ & \\
\hline Insulin treatment & & & & & & & $<0.001$ \\
\hline No & $8273(9.2)$ & $5370(5.97)$ & $2146(2.39)$ & $453(0.50)$ & $182(0.20)$ & $122(0.14)$ & \\
\hline Yes & $5114(27.7)$ & $2774(15.03)$ & $1554(8.42)$ & $491(2.65)$ & $218(1.18)$ & $77(0.42)$ & \\
\hline Smoking Status & & & & & & & 0.182 \\
\hline Smoker & $1573(10.7)$ & $968(6.58)$ & $441(3.00)$ & $104(0.71)$ & $45(0.31)$ & $15(0.10)$ & \\
\hline Past-smoker & 3486 (11.9) & $2085(7.13)$ & 991 (3.38) & $264(0.90)$ & $89(0.30)$ & $54(0.18)$ & \\
\hline Never-smoker & $8274(12.9)$ & $5060(7.89)$ & $2252(3.51)$ & $568(0.89)$ & $264(0.41)$ & $130(0.20)$ & \\
\hline Hypertension & & & & & & & $<0.001$ \\
\hline No & $1976(9.1)$ & $1275(5.87)$ & $516(2.38)$ & $128(0.58)$ & $36(0.17)$ & $21(0.10)$ & \\
\hline Yes & $11411(13.1)$ & $6869(7.89)$ & $3184(3.66)$ & $816(0.93)$ & $364(0.42)$ & $178(0.20)$ & \\
\hline Blood pressure (mm Hg) & & & & & & & $<0.001$ \\
\hline$\geq 140 / 90$ & $4487(15.4)$ & $2620(8.99)$ & $1316(4.52)$ & $338(1.16)$ & $143(0.49)$ & $70(0.24)$ & \\
\hline$<140 / 90$ & 7490 (10.9) & $4664(6.79)$ & $2007(2.92)$ & $484(0.70)$ & $224(0.33)$ & $111(0.16)$ & \\
\hline No HDL-cholesterol (mmol/L) & & & & & & & 0.272 \\
\hline$\geq 3.3$ & $2353(10.5)$ & $1437(6.41)$ & $632(2.82)$ & $183(0.82)$ & $65(0.29)$ & $36(0.16)$ & \\
\hline$<3.3$ & 8390 (12.6) & $5105(7.67)$ & 2366 (3.55) & $559(0.84)$ & $247(0.37)$ & $113(0.17)$ & \\
\hline
\end{tabular}

\section{DISCUSSION}

Our study provides data on the prevalence and severity of DR in patients with T2DM screened with retinal photography and whose DR category was recorded in their medical records. A longitudinal, 10-year follow-up of this cohort is planned in order to evaluate DR incidence, changes in DR severity and related complications.

It is well known that, due to the differences in baseline characteristics, the prevalence of DR is reported to be higher in clinical studies than in population based ones. We believe the figures from the latter to be underestimated. In our study, for example, patients with glaucoma and cataracts, and those attended by an ophthalmologist because they had VTDR, did not usually undergo retinal photography screening in primary care. In addition, a reduced number of patients who presented a greater number of complications and worse metabolic control was attended by an endocrinologist. Moreover in our study, differences among patients, with and without retinal photography, could affect the final results of DR prevalence.

In our work, $12.3 \%$ (CI $12.1 \%$ to $12.5 \%$ ) of the patients screened with retinal photography had some kind of DR and $1.4 \%$ suffered from VTDR. A DR prevalence rate did not concur with other studies in which incidence varied between $6 \%$ and $27.9 \%,{ }^{524}$ and $20.9 \%$ and $26.1 \%$ in Spain. ${ }^{78}$ A 2007 population-based study carried out in primary care, in which screening was performed with a direct ophthalmological examination by a specialist, reported a DR prevalence of $5.8 \% .^{21}$ In contrast, studies with patients with diabetes screened with retinal photography observed a DR prevalence ranging from $10.1 \%$ to $48.1 \%$. $^{6}$ The heterogeneity of the studies performed makes comparisons difficult and disguises the real prevalence of DR in the T2DM population attended in primary care.

The diabetic population in Catalonia is very well controlled (from a metabolic point of view) and our population is not a selected well controlled group. In another study by our group about metabolic control of glycaemia and cardiovascular risk factors in patients with T2DM in primary care in Catalonia (Spain) the mean (SD) A1C value was 7.15\% (1.5). ${ }^{21}$

Better control of T2DM could be the reason for the overall decrease in the incidence and prevalence of DR..$^{15}$ In agreement with prior studies, we observed three major DR risk factors: diabetes progression time, A1C levels and blood pressure control. ${ }^{10}{ }^{24}$ It is possible that the total exposure to the glycaemic load and cardiovascular risk factors over the years is reflected in the time of diabetes progression. As in other work, ${ }^{25}$ we noted that higher $\mathrm{A} 1 \mathrm{C}$ values were related to a greater prevalence of DR while higher levels of non-HDL cholesterol to a lesser one. Patients with DR had higher levels of UACR and lower levels of eGFR than patients without DR. Diabetes kidney disease and DR are linked to endothelial 
dysfunction; it is possible that microvascular lesions progress in a parallel manner in the kidney and the eye. Patients with diabetes kidney disease should, therefore, be considered at high risk for DR screening.

In each Primary Health Care Centre of Catalonia, a general practitioner (GP) trained in reading eye fundus images read the retinal photography. There is no existing strict quality control on our screening process, nevertheless, the professionals who perform and read the retinal photography have previously received the same regulated and accredited training. Moreover the professionals who read the fundus may consult with the ophthalmologist if they have any doubts. Although the studies that have evaluated the agreement among GPs and ophthalmologists in evaluating retinal images in Spain showed a good concordance, we have to accept that the screening of DR performed by several professionals might have influenced the final results.

\section{Strengths and limitations of the study}

Our study has some strengths and limitations. The main strengths are access to retinal photography screening data, information about DR category in the patients' clinical records, use of a population based database, and sample size. It is noteworthy that we were dealing with patients with T2DM attended in primary care, most of whom followed the corresponding controls. As a consequence, we believe our results to be extremely relevant for clinical practice. Among our limitations, as it is a database study, not all patients with T2DM underwent retinal photography and had the corresponding DR categories registered in their clinical records.

In addition, patients with VTDR, who were attended by an ophthalmologist or endocrinologist, could have been poorly represented.

Another limitation of our study is the duration of diabetes mellitus in the DR population is higher than observed in the results. The source of information used in this study is the SIDIAP, a computerised database containing anonymised patient records for the 5.8 million people registered with a GP in the Catalan Health Institute. The SIDIAP contains all data entered into the ECAP database since it was first introduced in some practices in 1998, but until 2005 the system was not generalised and used systematically in every Catalan Health Institute practice. An unknown number of GPs recorded the surgery visit in the system as the diabetes diagnosis date and not the true date of diagnosis of diabetes. For that reason we think that the true duration of diabetes is higher but we think it has not influenced the lower prevalence of DR.

\section{CONCLUSIONS}

In summary, our study provides data on the prevalence of DR and VTDR in a sample of 108723 T2DM participants who were screened with retinal photography and had their DR category registered in their medical records. Our findings indicate that the real prevalence of DR and VTDR in T2DM individuals who were screened with retinal photography is lower than that published to date in the literature. Nevertheless, it is necessary to continue with cribbage and good control of risk factors in order to decrease the prevalence of DR.

${ }^{1}$ Primary Health Care Center Anglès, Gerència Territorial Girona, Institut Català de la Salut, Girona, Spain

${ }^{2}$ Unitat de Suport a la Recerca Girona, Institut Universitari d'Investigació en Atenció Primària Jordi Gol (IDIAP Jordi Gol), Girona, Spain

${ }^{3}$ Primary Health Care Center Martorell, Gerència Territorial Metropolitana Sud, Institut Català de la Salut, Barcelona, Spain
}

${ }^{4}$ Unitat de Suport a la Recerca Barcelona Ciutat, Institut Universitari d'Investigació en Atenció Primària Jordi Gol (IDIAP Jordi Gol), Barcelona, Spain

${ }^{5}$ Institut Universitari d'Investigació en Atenció Primària Jordi Gol (IDIAP Jordi Gol), Barcelona, Spain

${ }^{6}$ Primary Health Care Center Jordi Nadal (Salt), Gerència Territorial Girona, Institut Català de la Salut, Girona, Spain

${ }^{7}$ Primary Health Care Center Raval Sud, Gerencia d'Atenció Primària Barcelona Ciutat, Institut Catala de la Salut, Barcelona, Spain

${ }^{8}$ Primary Health Care Center La Mina, Gerència d'Atenció Primària Barcelona Ciutat, Institut Català de la Salut, Barcelona, Spain

${ }^{9}$ Universitat Autónoma de Barcelona, Bellaterra, Spain, Barcelona, Spain

Contributors AR-P and XM-T designed the study. AR-P, SM-J and XM-T researched the data and wrote and edited the manuscript. $A C$ analysed the data and reviewed the manuscript. JFB-DLP and JF-N contributed to discussion and reviewed and edited the manuscript.

Funding This study was supported by a grant from the IDIAP.

Competing interests None declared.

Ethics approval This study was approved by the Ethics Committee of the IDIAP Jordi Gol (protocol number P13/028) and was carried out in accordance with the principles of the 1996 Helsinki declaration.

Provenance and peer review Not commissioned; externally peer reviewed.

Open Access This is an Open Access article distributed in accordance with the Creative Commons Attribution Non Commercial (CC BY-NC 4.0) license, which permits others to distribute, remix, adapt, build upon this work non-commercially, and license their derivative works on different terms, provided the original work is properly cited and the use is non-commercial. See: http://creativecommons.org/ licenses/by-nc/4.0/

\section{REFERENCES}

1 Fong DS, Aiello L, Gardner TW, et al. American Diabetes Association. Retinopathy in diabetes. Diabetes Care 2004;27(Suppl 1):S84-7.

2 ACCORD Study Group. Diabetic retinopathy, its progression, and incident cardiovascular events in the ACCORD trial. Diabetes Care 2013;36:1266-71.

3 Kempen JH, O'Colmain BJ, Leske MC, et al. Eye Diseases Prevalence Research Group. The prevalence of diabetic retinopathy among adults in the United States. Arch Ophthalmol 2004;122:552-63.

4 Yau JW, Rogers SL, Kawasaki R, et al. Meta-Analysis for Eye Disease (META-EYE) Study Group. Global prevalence and major risk factors of diabetic retinopathy. Diabetes Care 2012;35:556-64.

5 Wong TY, Klein R, Islam FM, et al. Diabetic retinopathy in a multi-ethnic cohort in the United States. AmJ Ophthalmol 2006:141:446-55.

6 Ruta LM, Magliano DJ, Lemesurier R, et al. Prevalence of diabetic retinopathy in Type 2 diabetes in developing and developed countries. Diabet Med 2013;30:387-98

7 López IM, Diez A, Velilla S, et al. Prevalence of diabetic retinopathy and eye care in a rural area of Spain. Ophthalmic Epidemiol 2002;9:205-14.

8 Pedro RA, Ramon SA, Marc BB, et al. Prevalence and relationship between diabetic retinopathy and nephropathy, and its risk factors in the North-East of Spain, a population-based study. Ophthalmic Epidemiol 2010;17:251-65.

9 Kostev $V$ and Rathmann W. Diabetic retinopathy at diagnosis of type 2 diabetes in the UK: a database analysis. Diabetología 2013;56:109-11.

10 Zhang $X$, Saaddine JB, Chou CF, et al. Prevalence of diabetic retinopathy in the United States, 2005-2008. JAMA 2010;304:649-56.

11 Olafsdottir $\mathrm{E}$, Andersson DK, Dedorsson I, et al. The prevalence of retinopathy in subjects with and without type 2 diabetes mellitus. Acta Ophthalmol 2014;92:133-7.

12 Soriguer F, Goday A, Bosch-Comas A, et al. Prevalence of diabetes mellitus and impaired glucose regulation in Spain: the Di@bet.es Study. Diabetologia 2012;55:88-93.

13 Shaw JE, Sicree RA, Zimmet PZ. Global estimates of the prevalence of diabetes for 2010 and 2030. Diabet Res Clin Pract 2010:87:4-14.

14 Romero-Aroca P, Fernández-Balart J, Baget-Bernaldiz M, et al. Changes in the diabetic retinopathy epidemiology after 14 years in a population of Type 1 and 2 diabetic patients after the new diabetes mellitus diagnosis criteria and a more strict control of the patients.. J Diabetes Complications 2009;23:229-38.

15 Wong TY, Mwamburi M, Klein R, et al. Rates of progression in diabetic retinopathy during different time periods: a systematic review and meta-analysis. Diabetes Care 2009;32:2307-13.

16 Stratton IM, Kohner EM, Aldington SJ, et al. UKPDS 50: risk factors for incidence and progression of retinopathy in Type II diabetes over 6 years from diagnosis. Diabetologia 2001:44:156-63.

17 Chew EY, Ambrosius WT, Davis MD, et al. Effects of medical therapies on retinopathy progression in type 2 diabetes. N Engl J Med 2010;363:233-44 
18 Lunetta $M$, Infantone $L$, Calogero $A E$, et al. Increased urinary albumin excretion is a marker of risk for retinopathy and coronary heart disease in patients with type 2 diabetes mellitus. Diabetes Res Clin Pract 1998;40:45-51.

19 Hemmingsen B, Lund SS, Gluud C, et al. Targeting intensive glycaemic control versus targeting conventional glycaemic control for type 2 diabetes mellitus. Cochrane Database Syst Rev 2013;11:CD008143.

20 [No authors listed]. Tight blood pressure control and risk of macrovascular and microvascular complications in type 2 diabetes: UKPDS 38. UK Prospective Diabetes Study Group. BMJ 1998;317:703-13.

21 Vinagre I, Mata-Cases M, Hermosilla $\mathrm{E}$, et al. Control of glycemia and cardiovascular risk factors in patients with type 2 diabetes in primary care in Catalonia (Spain). Diabetes Care 2012;35:774-9.
22 Olson JA, Strachan FM, Hipwell JH, et al. A comparative evaluation of digital imaging, retinal photography and optometrist examination in screening for diabetic retinopathy. Diabet Med 2003;20:528-34.

23 Wilkinson CP, Ferris FL III, Klein RE, et al., Global Diabetic Retinopathy Project Group. Proposed international clinical diabetic retinopathy and diabetic macular edema disease severity scales. Ophthalmology 2003;110:1677-82.

24 Tapp RJ, Shaw JE, Harper CA, et al. The prevalence of and factors associated with diabetic retinopathy in the Australian population. Diabetes Care 2003;26:1731-7.

25 Molyneaux LM, Constantino MI, McGill M, et al. Better glycaemic control and risk reduction of diabetic complications in Type 2 diabetes: comparison with the DCCT. Diabetes Res Clin Pract 1998;42:77-83. 